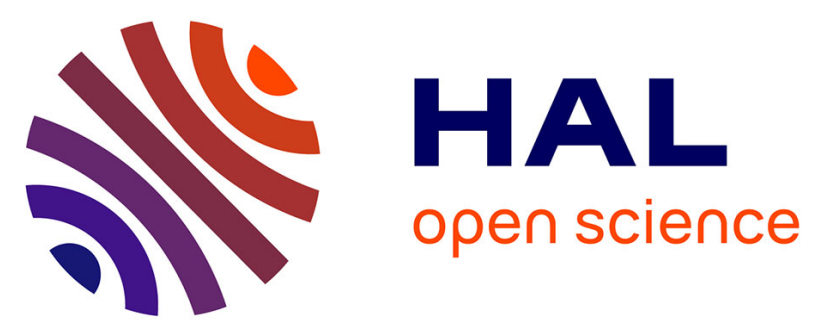

\title{
Toward the understanding of water-in-salt electrolytes: Individual ion activities and liquid junction potentials in highly concentrated aqueous solutions
}

\author{
Damien Degoulange, Nicolas Dubouis, Alexis Grimaud
}

\section{- To cite this version:}

Damien Degoulange, Nicolas Dubouis, Alexis Grimaud. Toward the understanding of water-in-salt electrolytes: Individual ion activities and liquid junction potentials in highly concentrated aqueous solutions. Journal of Chemical Physics, 2021, 155 (6), pp.064701. 10.1063/5.0058506 . hal-03332149

HAL Id: hal-03332149

https://hal.science/hal-03332149

Submitted on 2 Sep 2021

HAL is a multi-disciplinary open access archive for the deposit and dissemination of scientific research documents, whether they are published or not. The documents may come from teaching and research institutions in France or abroad, or from public or private research centers.
L'archive ouverte pluridisciplinaire HAL, est destinée au dépôt et à la diffusion de documents scientifiques de niveau recherche, publiés ou non, émanant des établissements d'enseignement et de recherche français ou étrangers, des laboratoires publics ou privés. 


\section{Towards the understanding of Water-in-Salt electrolytes: Individual}

ion activities and liquid junction potentials in highly concentrated

\section{aqueous solutions}

Damien Degoulange $e^{1,2,3}$, Nicolas Dubouis ${ }^{1,2,3}$, Alexis Grimaud $^{1,2,3^{*}}$

1. Chimie du Solide et de l’Energie, Collège de France, UMR 8260, 75231 Paris Cedex 05

2. Sorbonne Université, 75006 Paris, France

3. Réseau sur le Stockage Electrochimique de l'Energie (RS2E), CNRS FR3459, 33 rue Saint Leu, 80039 Amiens Cedex, France

*Corresponding author:

Alexis Grimaud: alexis.grimaud@college-de-france.fr 


\section{Abstract}

Highly concentrated electrolytes were recently proposed to improve the performances of aqueous electrochemical systems by delaying the water splitting and increasing the operating voltage for battery applications. While advances were made regarding their implementation in practical devices, debate exists regarding the physical origin for the delayed water reduction occurring at the electrode/electrolyte interface. Evidently, one difficulty resides in our lack of knowledge regarding ions activity arising from this novel class of electrolyte, it being necessary to estimate the Nernst potential of associated redox reactions such as $\mathrm{Li}^{+}$intercalation or the hydrogen evolution reaction. In this work, we first measured the potential shift of electrodes selective to either $\mathrm{Li}^{+}, \mathrm{H}^{+}$or $\mathrm{Zn}^{2+}$ ions from diluted to highly concentrated regimes in $\mathrm{LiCl}$ or LiTFSI solutions. Observing similar shifts for these different cations and environments, we establish that shifts in redox potentials from diluted to highly concentrated regime originates in large from an increased junction potential, which is dependent on the ions activity coefficients that increase with concentration. While our study shows that single ion activity coefficients, unlike mean ion activity coefficients, cannot be captured by any electrochemical means, we demonstrate that protons concentration increases by one to two orders of magnitude from 1 mol. $\mathrm{kg}^{-1}$ to $15-20$ mol. $\mathrm{kg}^{-1}$ solutions. Combined with the increased activity coefficients, this phenomenon increases the activity of protons and thus increases the $\mathrm{pH}$ of highly concentrated solutions which appears acidic. 


\section{Introduction}

Highly concentrated aqueous solutions play a key role in both biological and electrochemical systems. Indeed, biological environments are often described as molecularly crowded with up to $40 \%$ of the total volume of some cells that can be occupied by macromolecules. ${ }^{1,2}$ The impact of such crowded environments is twofold. On the one hand, the diffusion of soluble species is slowed down by several orders of magnitude compared to diluted solutions, ${ }^{1,3}$ while on the other hand, the changes in chemical activities due to the crowded environment induce a shift in the equilibrium of biochemical reactions..$^{1-3}$ In addition to biological systems, highly concentrated aqueous electrolytes are also used for electrochemical applications such as the chlor-alkali process or recently in aqueous Li-ion batteries. ${ }^{4,5}$

In aqueous electrochemical systems, water can be oxidised at the anode following the so-called oxygen evolution reaction (OER: $2 \mathrm{H}_{2} \mathrm{O}=\mathrm{O}_{2}(\mathrm{~g})+4 \mathrm{H}^{+}{ }_{(\mathrm{aq})}+4 \mathrm{e}^{-}$) or reduced at the cathode following the hydrogen evolution reaction (HER: $2 \mathrm{H}_{2} \mathrm{O}+2 \mathrm{e}^{-}=\mathrm{H}_{2}(\mathrm{~g})+2 \mathrm{HO}^{-}(\mathrm{aq})$ ). When operating between the HER and OER reversible potentials, water molecules are thermodynamically stable giving a thermodynamic stability window of $1.23 \mathrm{~V}$ at room temperature. Moreover, given the slow kinetics for complex reactions such as the OER and the HER involving the transfer of numerous protons and electrons, overpotentials must be overcame to split water and thus the electrochemical stability window of water is broaden to about 1.5-2 V for practical diluted electrolytes. ${ }^{6}$ Unfortunately, that window remains too small for designing energy-dense rechargeable aqueous batteries. More specifically, the HER which lies at $\approx 2.6 \mathrm{~V}$ vs. $\mathrm{Li}^{+} / \mathrm{Li}$ at $\mathrm{pH} 7$ only allows for the use of negative electrodes materials such as 
sulphides, alike $\mathrm{Mo}_{6} \mathrm{~S}_{8}$, but forbids the use of conventional negative electrode materials functioning at lower potentials than the HER.

Such paradigm was recently questioned by reports that highly concentrated aqueous electrolytes could enlarge the electrochemical stability window of water up to $3 \mathrm{~V}^{7-11}$ Nevertheless, the origin for such enlargement, it being kinetics or thermodynamics, remains largely debated to date. ${ }^{12-14}$ Indeed, the lack of knowledge regarding critical physical parameters such as ions activity in these highly concentrated solutions hampers accessing to the reversible potentials for reactions such as the HER. For instance, the activity of protons, equivalent to the $\mathrm{pH}$, which has been subject to controversy with reports of acidic $\mathrm{pH}$ being measured in highly concentrated solutions of neutral salts in which it is presumably low, ${ }^{15}$ is preventing us to estimate the cathodic stability of the electrolyte in this regime. Moreover, when moving from the ideal infinite dilution regime to a highly concentrated one, not only the potential for the HER is modified but the one of other reactions such as $\mathrm{Li}^{+}$reversible intercalation as well. Indeed, preliminary studies suggested that when increasing the concentration from a diluted 1 mol. $\mathrm{kg}^{-1}$ system to a so-called water-in-salt electrolyte (WiSE) with 21 mol.kg-1 of organic Li-salt, namely lithium bis(trifluoromethanesulfonyl)imide (LiTFSI), the reversible potential for cations (de)intercalation shifts positively by $\approx 200 \mathrm{mV}$ as the result of an increased activity of Li-ions (Fig. 1a). ${ }^{9}$

Hence, from a practical point of view, changes in ions activity are of prime importance. Indeed, if the activity of Li-ions and protons in concentrated solutions evolve differently as a function of salt concentration, lithium intercalation can be favoured in electrode materials such as $\mathrm{Mo}_{6} \mathrm{~S}_{8}$ at the expense of the HER (Fig. 1a), or vice versa (Fig. 1b). Such activity shifts would thus directly 
impact the reactivity at the electrode-electrolyte interface and affect the performances of electrochemical aqueous systems.
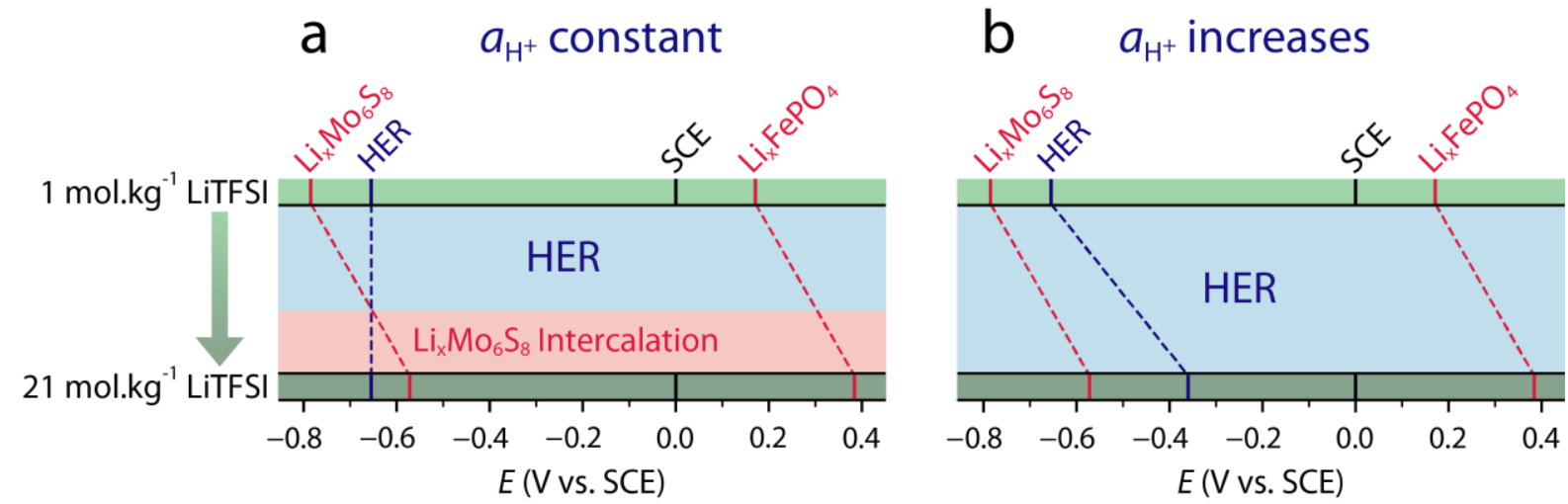

Fig. 1: Potential shifts for the HER and the $\mathrm{Li}^{+}$intercalation in $\mathrm{LiFePO}_{4}$ and $\mathrm{Mo}_{6} \mathrm{~S}_{8}$, from a 1 mol.kg ${ }^{-1}$ LiTFSI electrolyte to a $21 \mathrm{~mol} . \mathrm{kg}^{-1}$ LiTFSI WiSE. (a) Chemical shifts considering the activity of protons constant, equivalent to a constant $\mathrm{pH}=7$. (b) Chemical shifts considering an increasing activity of protons, equivalent to a decreasing $\mathrm{pH}$ from $\mathrm{pH}=7$ at $1 \mathrm{~mol} . \mathrm{kg}^{-1}$ of LiTFSI to $\mathrm{pH}=2$ for $21 \mathrm{~mol}^{\mathrm{kg}}{ }^{-1}$ of LiTFSI. ${ }^{15}$

In solution, the activity of a species $S, a_{S}$, is the product of its concentration, $c_{S}$, and its activity coefficient, $\gamma_{S}^{16}$ :

$$
a_{S}=\gamma_{S} c_{S} \#(1)
$$

From a fundamental point of view, our current understanding of variations of the activity of species in aqueous systems emerges from complementary theoretical and experimental studies. In very diluted electrolytes, the activity coefficients can be approximated through the Debye and Hückel limiting law:

$$
\ln \left(\gamma_{\text {salt }}\right)=-A\left|z_{+} z_{-}\right| \sqrt{I} \#(2)
$$

where $\gamma_{\text {salt }}=\sqrt{\gamma_{+} \gamma_{-}} ; I=\frac{1}{2} \sum_{i= \pm} c_{i} z_{i}^{2} ; A=\frac{e^{2} B}{8 \pi \varepsilon_{0} \varepsilon_{r} k_{B} T} \quad ; \quad B=\sqrt{\frac{2}{\varepsilon_{0} \varepsilon_{r} R T}}$ 
with $\gamma_{\text {salt }}$ the mean activity coefficient of the salt, $\gamma_{+}$the cation activity coefficient, $\gamma_{-}$the anion activity coefficient, $I$ the ionic strength, $c_{i}$ the concentration of ion $i, z_{i}$ the charge of ion $i, e$ the unit charge, $\varepsilon_{0}$ the vacuum permittivity, $\varepsilon_{r}$ the relative permittivity of the solvent, $k_{B}$ the Boltzmann constant, $R$ the gas constant and $T$ the temperature, all given in $\mathrm{SI}$ units. ${ }^{16}$ In the Debye-Hückel model, the solvent is introduced as a dielectric continuum with a fixed dielectric constant. However, for increased concentrations, the presence of ions is influencing the physical properties of the medium leading to the development of a model with a dielectric constant dependant on ions concentrations. ${ }^{17}$ Nevertheless, all the above-mentioned models consider the solvent as a dielectric continuum in which solvent-ions interactions are modelled with a Coulomb law between the ions and an average dielectric continuum. ${ }^{18}$ While such assumption seems reasonable as long as the ions solvation sphere is kept constant, switching from diluted to highly concentrated aqueous electrolytes the amount of ions-water molecules interactions will decrease, as for a WiSE in which the salt concentration ( 21 mol. $\mathrm{kg}^{-1}$ of LiTFSI) corresponds to a stoichiometry of 1:2.6 LiTFSI to water molecules. At such concentration, molecular ion-ion interactions such as ion pairing or bigger ionic aggregates are significantly interfering with the solvation shell of ions ${ }^{7,19-21}$ but are only poorly modelled via a dielectric continuum. Eventually, equations such as the one developed by Pitzer ${ }^{22-24}$ enable the description of ions activity in concentrated electrolytes but are only empirical and do not explain the physics behind any changes in activity coefficients. Consequently, new models are currently being developed to gain a molecular understanding of both solvent-ions and ions-ions interactions and their impact on single ions activity coefficients in highly concentrated electrolytes. ${ }^{18,25}$ 
Unfortunately, experimental data regarding activity coefficient for ions in highly concentrated solutions pertinent to electrochemical devices are scarce. While the activity of water can be measured using vapour pressure and the mean activity coefficient of a salt determined via osmotic coefficient ${ }^{26}$, the activity of individual ions can theoretically be approximated from the Nernst potential of ion selective electrodes (ISE) at equilibrium. Several studies have thus been conducted on individual ions activity in such highly concentrated electrolytes, all pointing towards the increase of ions activity as a function of concentration. ${ }^{18,25}$ However, questions remain regarding the validity of such measurements, in part due to difficulties in properly correcting for experimental artefacts such as junction potentials, often completely neglected. Thus, in this work, we discuss our ability to accurately measure single or mean ions activities in highly concentrated electrolytes by the means of electrochemical measurements. For that, we selected two systems, the $\mathrm{H}_{2} \mathrm{O}-\mathrm{Cl}^{-}$one relevant to the chlor-alkali process and the $\mathrm{H}_{2} \mathrm{O}-\mathrm{TFSI}$ one relevant to the battery field. For these systems, $\mathrm{Li}^{+}, \mathrm{Zn}^{2+}$ and $\mathrm{H}^{+}$cations were studied, giving access to monovalent, divalent and proton chemistries.

\section{Theory and Approximations}

First, a redox couple for an oxidising (Ox) and a reducing (Red) agent in solution is considered, with its Nernst potential $E_{N}$ being described as follow:

$$
\begin{gathered}
\text { Ox }+n \mathrm{e}^{-}=\operatorname{Red} \#(3) \\
E_{N}=E_{\text {Ox } / \text { Red }}^{\circ}+\frac{R T}{n F} \ln \left(\frac{c_{\mathrm{Ox}}}{c_{\text {Red }}}\right)+\frac{R T}{n F} \ln \left(\frac{\gamma_{\mathrm{Ox}}}{\gamma_{\text {Red }}}\right) \#(4)
\end{gathered}
$$


with, $F$ the Faraday constant, $E^{\circ}{ }_{0 x / R e d}$ the standard potential of the redox couple, $c_{\mathrm{Ox}}$ the concentration of the oxidizing agent, $c_{\mathrm{Red}}$ the concentration of the reducing agent, $\gamma_{\mathrm{Ox}}$ the activity coefficients of the oxidizing agent and $\gamma_{\text {Red }}$ the activity coefficients of the reducing agent. ${ }^{27}$ In this study, three cations have been studied, two monovalent $\mathrm{Li}^{+}$and $\mathrm{H}^{+}$and a divalent one $\mathrm{Zn}^{2+}$, as well as an anion $\mathrm{Cl}^{-}$, considering the following Nernst equation and redox equations:

$$
\begin{gathered}
x \mathrm{Li}^{+}{ }_{(\mathrm{aq})}+x \mathrm{e}^{-}+(1-x) \mathrm{LiFePO}_{4(\mathrm{~s})}+x \mathrm{FePO}_{4(\mathrm{~s})}=\mathrm{LiFePO}_{4(\mathrm{~s})} \#(5) \\
E_{N}\left(\mathrm{Li}^{+} / \mathrm{Li}^{+}-\mathrm{ISE}\right)=E_{\mathrm{Li}^{+} / \mathrm{Li}^{+}-\mathrm{ISE}}^{\circ}+\frac{R T}{F} \ln \left(a_{\mathrm{Li}^{+}}(m)\right) \#(6) \\
2 \mathrm{H}^{+}{ }_{(\mathrm{aq})}+2 \mathrm{e}^{-}=\mathrm{H}_{2(\mathrm{~g})} \#(7) \\
E_{N}\left(\mathrm{H}^{+} / \mathrm{H}^{+}-\mathrm{ISE}\right)={E^{\circ} \mathrm{H}^{+} / \mathrm{H}^{+}-\mathrm{ISE}}^{\circ}+\frac{R T}{F} \ln \left(a_{\mathrm{H}^{+}}(m)\right) \#(8) \\
\mathrm{Zn}^{2+}{ }_{(\mathrm{aq})}+2 \mathrm{e}^{-}=\mathrm{Zn}_{(\mathrm{s})} \#(9) \\
E_{N}\left(\mathrm{Zn}^{2+} / \mathrm{Zn}^{2+}-\mathrm{ISE}\right)=E_{\mathrm{Zn}^{2+} / \mathrm{Zn}^{2+}-\mathrm{ISE}}^{\circ}+\frac{R T}{2 F} \ln \left(a_{\mathrm{Zn}^{2+}}(m)\right) \#(10) \\
\mathrm{AgCl}_{(\mathrm{s})}+\mathrm{e}^{-}=\mathrm{Ag}_{(\mathrm{s})}+\mathrm{Cl}^{-}{ }_{(\mathrm{aq})} \#(11) \\
E_{N}\left(\mathrm{Cl}^{-}-{\left.\mathrm{ISE} / \mathrm{Cl}^{-}\right)}^{\circ}={E^{\circ} \mathrm{Cl}^{-}-\mathrm{ISE} / \mathrm{Cl}^{-}}^{-} \frac{R T}{F} \ln \left(a_{\mathrm{Cl}}(m)\right) \#(12)\right.
\end{gathered}
$$

ISEs used to study $\mathrm{Li}^{+}, \mathrm{H}^{+}$and $\mathrm{Zn}^{2+}$ were respectively a half lithiated $\mathrm{LiFePO}_{4} / \mathrm{FePO}_{4}$ electrode $\left(\mathrm{Li}^{+}-\mathrm{ISE}\right)^{28}$, a reversible hydrogen electrode (RHE) $\left(\mathrm{H}^{+}-\mathrm{ISE}\right)$ and a metallic $\mathrm{Zn}$ electrode $\left(\mathrm{Zn}^{2+}-\mathrm{ISE}\right)$ 
while a commercial $\mathrm{Cl}^{-}$selective electrode was used as $\mathrm{Cl}^{-}$-ISE (see details in the Materials and Methods section).

Experimentally, the accessible quantity is the open circuit voltage (OCV), i.e. the difference between the potential of the working electrode $\left(E_{W E}\right)$ and the potential of a reference electrode $\left(E_{S C E}\right)$, in our case a saturated calomel electrode (SCE). When using an ion-sensitive electrode (ISE), the OCV is dependent on the molality $m$ via the Nernst potential of the redox couple $\left(E_{N}\right)$ as well as the liquid junction potential $\left(\phi^{m}-\phi^{S C E}\right)$ arising from the interface between the electrolyte at a molality $m$ with an electric potential $\phi^{m}$ and the solution of the reference electrode (SCE) with an electric potential $\phi^{S C E} \cdot{ }^{27}$ Our electrochemical cell and the measured OCV can thus be described as follow:

$$
\begin{gathered}
\mathrm{Hg} / \mathrm{Hg}_{2} \mathrm{Cl}_{2} / \mathrm{KCl}_{\text {sat }} / \operatorname{salt}(m) / \mathrm{ISE} \\
\mathrm{OCV}(m)=E_{W E}(m)-E_{S C E}=E_{N}(m)-E_{S C E}+\left(\phi^{m}-\phi^{S C E}\right) \#
\end{gathered}
$$

First, we compared the OCV values measured at a molality $m$ using a SCE $(\operatorname{OCV}(m))$ with the OCV measured in a concentration cell (CC) between molality $m$ and a molality of reference $\left(m_{R e f}\right)$ using no reference electrode $\left(\operatorname{OCV}_{\mathrm{CC}}(m)\right)$ which is given by:

$$
\begin{gathered}
\text { ISE } / \operatorname{salt}\left(m_{R e f}\right) / \operatorname{salt}(m) / \mathrm{ISE} \\
\operatorname{OCV}_{\mathrm{CC}}(m)=E_{N}(m)-E_{N}\left(m_{R e f}\right)+\left(\phi^{m}-\phi^{m_{R e f}}\right) \#(14)
\end{gathered}
$$

In a system containing $\mathrm{Li}^{+}$cations and using a $\mathrm{Li}^{+}-\mathrm{ISE}$, the evolution of the OCV values as a function of salt molality are found perfectly similar in both configuration (Fig. 2a and Fig. 2b), thus demonstrating the equivalence between these two configurations (Fig. $2 \mathrm{c}$ and Fig. $2 \mathrm{~d}$ ). As 
a consequence, we establish that the electrode potential of the SCE $\left(E_{S C E}\right)$ and the electric potential of the $\mathrm{KCl}$ saturated solution of the $\operatorname{SCE}\left(\phi^{S C E}\right)$ can be cancelled by taking the difference $\operatorname{OCV}(m)-\operatorname{OCV}\left(m_{\text {Ref }}\right)$ (Fig. S1):

$$
\begin{aligned}
\operatorname{OCV}(m)-\operatorname{OCV}\left(m_{\text {Ref }}\right) \\
=\left[E_{N}(m)-E_{S C E}+\left(\phi^{m}-\phi^{S C E}\right)\right]-\left[E_{N}\left(m_{R e f}\right)-E_{S C E}+\left(\phi^{m_{R e f}}-\phi^{S C E}\right)\right] \\
\quad=E_{N}(m)-E_{N}\left(m_{R e f}\right)+\left(\phi^{m}-\phi^{m_{R e f}}\right)=\operatorname{OCV}_{\mathrm{CC}}(m) \#(15)
\end{aligned}
$$

a

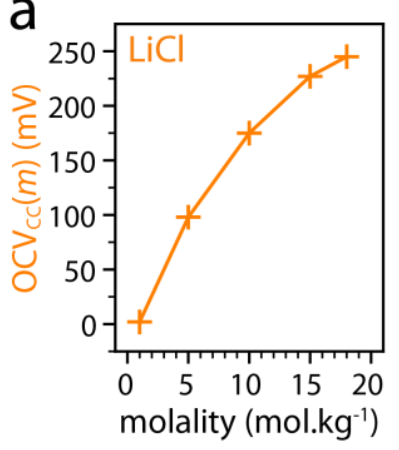

C

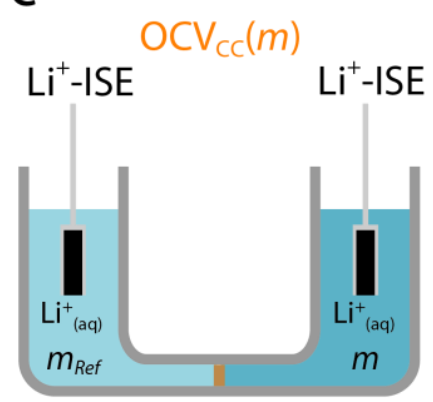

b
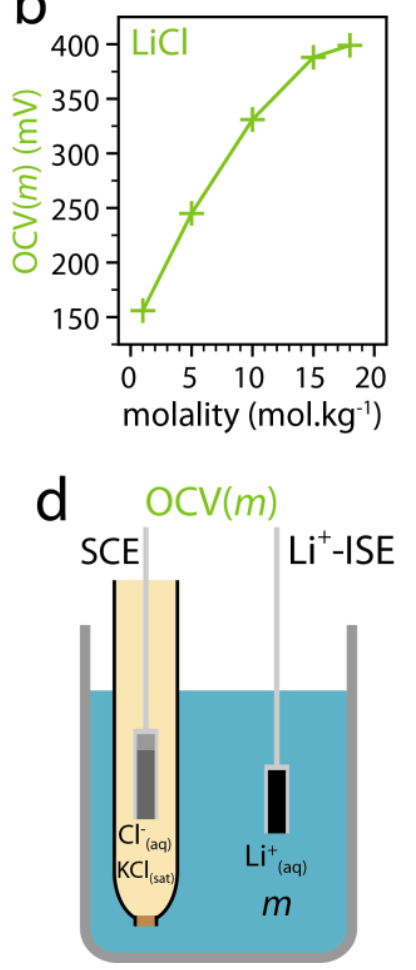

Fig. 2: OCV values measured from 1 mol. $\mathrm{kg}^{-1}$ to $18 \mathrm{~mol} . \mathrm{kg}^{-1} \mathrm{LiCl}$ with (a) a concentration cell and (b) using a SCE reference electrode. (c) and (d) are schemes representing these two configurations.

Such result was not evident experimentally-wise regarding the electrical potentials since, as highlighted by Bard and Faulkner, ${ }^{27}$ such experiments are strongly dependent on the nature of

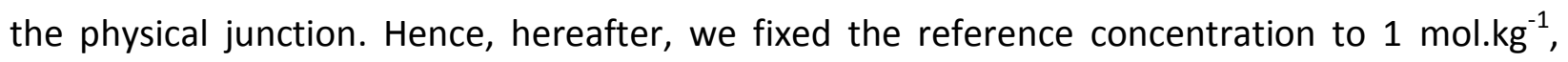


value which is i) high enough to enable to sum and cancel electrical potentials, ii) widely discussed in previous literature and thus enabling us to compare with our findings ${ }^{9,11}$ and iii) low enough not to be considered as being within the "super-concentrated" regime. Moreover, as most of the organic salts used to prepare the electrolytes are very costly, and for the sake of simplicity, the SCE configuration (Fig. 2d) was privileged in the following.

Having demonstrated the equivalence between these two configurations, the difference between $\operatorname{OCV}(m)$ and $\operatorname{OCV}\left(m_{R e f}\right)$, denoted $\Delta E$ in the following, can be split into a Nernstian part $\left(\Delta E_{N}\right)$ and a liquid junction part $\left(\Delta E_{L J P}\right)$ and expressed as:

$$
\begin{gathered}
\Delta E=\operatorname{OCV}(m)-\operatorname{OCV}\left(m_{R e f}\right)=\Delta E_{N}+\Delta E_{L J P} \#(16) \\
\text { with } \Delta E_{N}=E_{N}(m)-E_{N}\left(m_{R e f}\right) \#(17) \\
\text { and } \Delta E_{L J P}=\left(\phi^{m}-\phi^{m_{R e f}}\right) \#(18)
\end{gathered}
$$

The Nernstian part $\Delta E_{N}$ described in details for each ISE by eq. S1 to S20 can be further split into two parts associated with the change of concentration $\left(\Delta E_{N}^{c}\right)$ and the change of activity coefficient $\left(\Delta E_{N}^{\gamma}\right)$ :

$$
\begin{gathered}
\Delta E_{N}=\Delta E_{N}^{c}+\Delta E_{N}^{\gamma} \#(19) \\
\Delta E_{N}^{c}=\frac{R T}{n F} \ln \left(\frac{c_{\text {Ox }}(m)}{c_{\text {Ox }}\left(m_{\text {Ref }}\right)} \frac{c_{\text {Red }}\left(m_{R e f}\right)}{c_{\text {Red }}(m)}\right) \#(20) \\
\Delta E_{N}^{\gamma}=\frac{R T}{n F} \ln \left(\frac{\gamma_{\text {Ox }}(m)}{\gamma_{\text {Ox }}\left(m_{\text {Ref }}\right)} \frac{\gamma_{\text {Red }}\left(m_{\text {Ref }}\right)}{\gamma_{\text {Red }}(m)}\right) \#(21)
\end{gathered}
$$


Importantly, not only the Nernstian part depends on the activity of individual ions $a_{i}$, but the liquid junction potential as well:

$$
\Delta E_{L J P}=\frac{-R T}{F} \sum_{i} \int_{m_{R e f}}^{m} \frac{t_{i}}{z_{i}} \mathrm{~d} \ln a_{i} \#(22)
$$

with $a_{i}$ the activity of the ion $i, z_{i}$ the charge of the ion $i$ and $t_{i}$ the transport number of the ion $i^{27}$ Thus, the difference of OCV measured between two different solutions contains three parts, one being dependent on the concentration of the species involved in the redox couple, another one being dependent on their activity coefficient and the third one being dependent on the activity of all the ions in solution:

$$
\begin{aligned}
\Delta E=\operatorname{OCV}(m) & -\operatorname{OCV}\left(m_{\text {Ref }}\right)=\Delta E_{N}^{c}+\Delta E_{N}^{\gamma}+\Delta E_{L J P} \\
= & \frac{R T}{n F} \ln \left(\frac{c_{\mathrm{Ox}}(m)}{c_{\mathrm{Ox}}\left(m_{\text {Ref }}\right)} \frac{c_{\mathrm{Red}}\left(m_{\text {Ref }}\right)}{c_{\mathrm{Red}}(m)}\right)+\frac{R T}{n F} \ln \left(\frac{\gamma_{\mathrm{Ox}}(m)}{\gamma_{\mathrm{Ox}}\left(m_{\text {Ref }}\right)} \frac{\gamma_{\mathrm{Red}}\left(m_{\text {Ref }}\right)}{\gamma_{\text {Red }}(m)}\right) \\
& +\frac{-R T}{F} \sum_{i} \int_{m_{\text {Ref }}}^{m} \frac{t_{i}}{z_{i}} \mathrm{~d} \ln a_{i}
\end{aligned}
$$

Evidently, with this in mind, difficulties in accurately measuring single ion activities of species in solutions can be foreseen, as discussed below.

\section{Results}

\section{Effect of salt molality on the shift of open circuit voltage measured for different cations}

The OCV values using a $\mathrm{Li}^{+}$-ISE were first measured as a function of $\mathrm{LiCl}$ and LiTFSI salt concentration, from diluted to highly concentrated electrolytes. The equilibrium potentials, plotted in Fig. 3a, shifts from $\approx 150 \mathrm{mV}$ vs SCE in $1 \mathrm{~mol} . \mathrm{kg}^{-1}$ solution to $\approx 375 \mathrm{mV}$ vs SCE in highly 
concentrated solutions. In Fig. 3b and Fig. 3c are plotted, respectively for LiCl and LiTFSI, the $\Delta E$ values extrapolated between given molalities $m$ and the reference molality $m_{R e f}=1 \mathrm{~mol}_{\mathrm{kg}} \mathrm{kg}^{-1}$. The Nernstian part associated to the change in $\mathrm{Li}^{+}$concentration $\Delta E_{N}^{c}$ was calculated and plotted, before to be subtracted from the potential shift to give the corresponding values of $\Delta E-\Delta E_{N}^{c}=\Delta E_{N}^{\gamma}+\Delta E_{L J P}$. Doing so, $\Delta E-\Delta E_{N}^{c}$ values close to each others are obtained for $\mathrm{LiCl}$ and LiTFSI (Fig. 3b and Fig. 3c). This observation suggests that the nature of the anion (organic or inorganic) has no drastic impact on the measured shift in potential, despite LiCl and LiTFSI aqueous solutions showing very different solvation structures as well as physical properties. $^{21}$
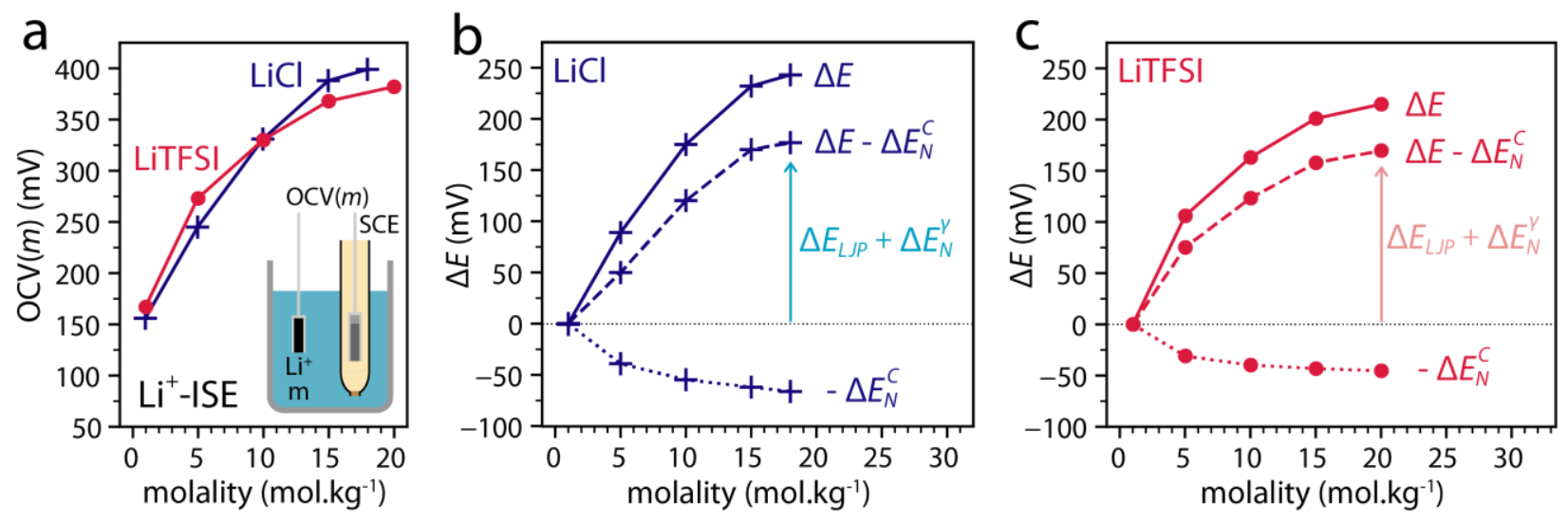

Fig. 3: Values of $\left(\Delta E_{L J P}+\Delta E_{N}^{\gamma}\right)$ extracted from the OCV measured with a Li' ${ }^{+}$-ISE in LiCl and LiTFSI solutions. (a) OCV values of the ISE-Li ${ }^{+}$in $\mathrm{LiCl}$ (blue) and LiTFSI (red) solutions. Values of $\Delta E$, calculated values of $\Delta E_{N}^{C}$ and values of $\left(\Delta E-\Delta E_{N}^{c}\right)$ (b) for $\mathrm{LiCl}$ and (c) for LiTFSI solutions.

To understand such trend, similar measurements were then performed in $\mathrm{Zn}^{2+}$-containing electrolytes using a $\mathrm{Zn}^{2+}-\mathrm{ISE}$. Two cases were considered, one similar to the previous measurement in which the concentration and the molality are simultaneously increased by adding a $\mathrm{Zn}^{2+}$-salt $\mathrm{ZnCl}_{2}$ and a second one in which the concentration of $\mathrm{Zn}^{2+}$ is fixed while the 
overall molality of the solution is increased by increasing the LiTFSI concentration. Doing so, pure $\mathrm{ZnCl}_{2}$ solutions ranging from $1 \mathrm{~mol} . \mathrm{kg}^{-1}$ to $20 \mathrm{~mol} . \mathrm{kg}^{-1}$ were compared to a fixed concentration of $10 \mathrm{mmol} . \mathrm{L}^{-1}(\mathrm{mM})$ of $\mathrm{Zn}(\mathrm{TFSI})_{2}$, which solubility is limited in water, dissolved in different LiTFSI solutions. As the concentration of $\mathrm{Zn}^{2+}$ at $m_{R e f}$ is $0.87 \mathrm{~mol}^{-1} \mathrm{~L}^{-1}$ for $\mathrm{ZnCl}_{2}$ while it is only of $10 \mathrm{mM}$ for $\mathrm{Zn}(\mathrm{TFSI})_{2}:$ LiTFSI, a $\approx 50 \mathrm{mV}$ difference in the absolutes values of OCVs at $m_{\text {Ref }}$ is observed (Fig. S2). However, when plotting $\Delta E-\Delta E_{N}^{c}$ (Fig. 4a), shifts of $\approx 250 \mathrm{mV}$ are found from 1 mol. $\mathrm{kg}^{-1}$ to 20 mol. $\mathrm{kg}^{-1}$ salt molalities for both $\mathrm{ZnCl}_{2}$ and $\mathrm{Zn}(\mathrm{TFSI})_{2}$ :LiTFSI solutions with only a slight deviation being observed at very large concentrations. Surprisingly, this result suggests that the shift in OCV, linked to both the junction potential and the activity coefficient, is independent i) on the concentration of the ion probed, it being the main salt or added in small quantities in a concentrated solution, and ii) on the ion environment which is presumably very different between $\mathrm{ZnCl}_{2}$ and LiTFSI solutions. Even more troubling, the shifts measured as a function of salt molality are close to the ones previously observed for LiTFSI and LiCl solutions using a $\mathrm{Li}^{+}$-ISE (Fig. 3), despite obvious differences in solvation structures existing between mono- and divalent cations. ${ }^{21,29}$

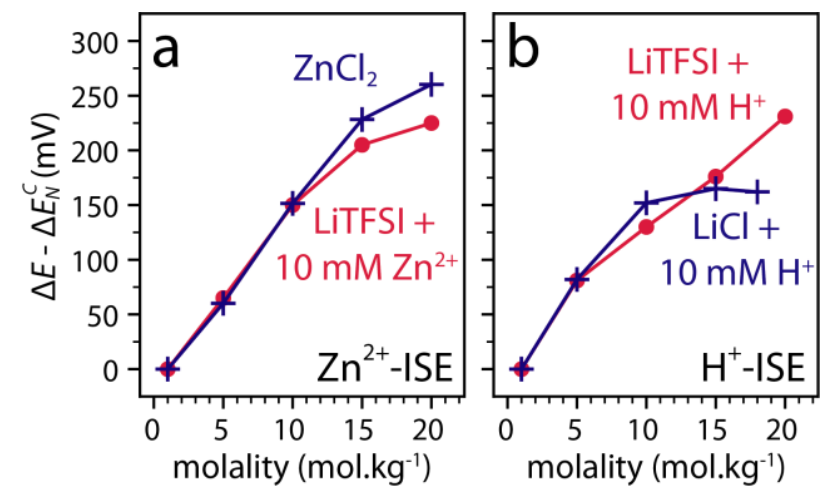


Fig. 4: Potential shift measured for a $\mathrm{Zn}^{2+}$-ISE and a $\mathrm{H}^{+}$-ISE as a function of salt molalities. (a) $\left(\Delta E-\Delta E_{N}^{c}\right)$ values of a $\mathrm{Zn}^{2+}$-ISE in $\mathrm{ZnCl}_{2}$ solutions (blue) and $\left(\Delta E-\Delta E_{N}^{c}\right.$ ) values of a $\mathrm{Zn}^{2+}$-ISE in LiTFSI solutions with $10 \mathrm{mM}$ of added $\mathrm{Zn}(\mathrm{TFSI})_{2}$ (red). (b) $\left(\Delta E-\Delta E_{N}^{c}\right)$ values of a $\mathrm{H}^{+}$-ISE in $\mathrm{LiCl}$ solutions with $10 \mathrm{mM}$ of added $\mathrm{HClO}_{4}$ (blue) and $\left(\Delta E-\Delta E_{N}^{c}\right)$ values of a $\mathrm{H}^{+}$-ISE in a LiTFSI solution with $10 \mathrm{mM}$ of added $\mathrm{HClO}_{4}$ (red).

Startled by this observation, shifts in potential from diluted to highly concentrated $\mathrm{LiCl}$ and LiTFSI solutions in which $10 \mathrm{mM}$ of $\mathrm{HClO}_{4}$ is added were measured for a third cation, protons, using a $\mathrm{H}^{+}$-ISE (Fig. 4b and Fig. S3). For both series the concentration of protons is fixed to 10 $\mathrm{mM}$ by addition of $\mathrm{HClO}_{4}$, thus the concentration term between two given Li-salt concentrations $\Delta E_{N}^{c}$ is null (eq. S11 to S15). Similar shifts of $\approx 200 \mathrm{mV}$ are measured from 1 mol. $\mathrm{kg}^{-1}$ to 15 mol.kg- $\mathrm{kg}^{-1}$ both $\mathrm{LiCl}$ and LiTFSI solutions with a deviation observed for $\mathrm{LiCl}$ near the saturation limit (Fig. 4b). Furthermore, when compared to the results previously obtained for $\mathrm{Li}^{+}$and $\mathrm{Zn}^{2+}$, fairly comparable values are measured (Fig. 5). These results thus lead to the conclusion that, for either inorganic $\left(\mathrm{Cl}^{-}\right)$or organic $\left(\mathrm{TFSI}^{-}\right)$anions, the shifts in potential measured for $\mathrm{Li}^{+}, \mathrm{Zn}^{2+}$ or $\mathrm{H}^{+}$cations are fairly comparable when subtracting for the concentration term (Fig. 5a and Fig. 5b, respectively). Thus, we demonstrate that neither the nature nor the concentration of the cation or the environment around the cation drastically impacts $\Delta E_{N}^{\gamma}+\Delta E_{L J P}$, term which is directly accessible by electrochemical means. These observations raise obvious questions, owing to the very different chemistries involved and for which one would expect single ion activity coefficients to drastically differ in all the cases studied in this work. 


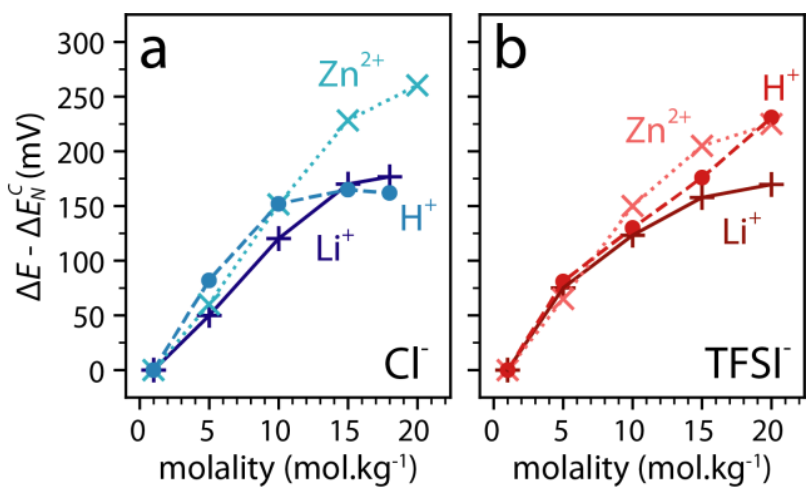

Fig. 5: $\left(\Delta E-\Delta E_{N}^{c}\right)$ values measured with $\mathrm{Li}^{+}$-ISE compared to that measured with an $\mathrm{H}^{+}$-ISE and a $\mathrm{Zn}^{2+}$ ISE in (a) $\mathrm{LiCl}, \mathrm{LiCl}+10 \mathrm{mM} \mathrm{HClO}_{4}$ and $\mathrm{ZnCl}_{2}$, respectively, and (b) LiTFSI, LiTFSI $+10 \mathrm{mM} \mathrm{HClO}_{4}$ and LiTFSI + $10 \mathrm{mM} \mathrm{Zn(TFSI})_{2}$ solutions, respectively.

Effect of salt molality on the junction potential 
To access the shift in potential arising from a change in activity coefficients $\Delta E_{N}^{\gamma}$, the junction potential $\Delta E_{L J P}$ must be precisely known. Unfortunately, the activity of ions and thus the activity coefficients of individual ions are intrinsically correlated to the liquid junction potential (eq. 22), making the exact determination of junction potentials mathematically irresolvable without approximations. ${ }^{27}$ Several approximations were thus previously proposed, one of the most acclaimed ones being the Henderson equation which can be applied to any type of liquid junctions:

$$
\begin{aligned}
\Delta E_{L J P}= & \left(\phi^{m}-\phi^{S C E}\right)-\left(\phi^{m_{R e f}}-\phi^{S C E}\right) \\
= & \left(\frac{\sum_{i} \frac{\left|z_{i}\right| u_{i}}{z i}\left(c_{i}(m)-c_{i}^{S C E}\right)}{\sum_{i}\left|z_{i}\right| u_{i}\left(c_{i}(m)-c_{i}^{S C E}\right)} \frac{R T}{F} \ln \frac{\sum_{i}\left|z_{i}\right| u_{i} c_{i}^{S C E}}{\sum_{i}\left|z_{i}\right| u_{i} c_{i}(m)}\right) \\
& -\left(\frac{\sum_{i} \frac{\left|z_{i}\right| u_{i}}{z i}\left(c_{i}\left(m_{R e f}\right)-c_{i}^{S C E}\right)}{\sum_{i}\left|z_{i}\right| u_{i}\left(c_{i}\left(m_{R e f}\right)-c_{i}^{S C E}\right)} \frac{R T}{F} \ln \frac{\sum_{i}\left|z_{i}\right| u_{i} c_{i}^{S C E}}{\sum_{i}\left|z_{i}\right| u_{i} c_{i}\left(m_{R e f}\right)}\right)
\end{aligned}
$$

with $c_{i}(m)$ the concentration of the ion $i$ at molality $m, c_{i}^{S C E}$ the concentration of the ion in the $\mathrm{KCl}_{\text {sat }}$ solution of the SCE, $u_{\mathrm{i}}$ the mobility of the ion $i$ in infinitely diluted regimes and $z_{i}$ the charge of the ion $i^{27}$

To apply the Henderson equation, two assumptions are made: i) the activities of ions are approximated to be equal to the concentration of ions in solution at each point of the junction and ii) the mobility of ions in solutions is independent of the molality and equal to the mobility measured in infinitely diluted regimes. ${ }^{27}$ Doing so, the liquid junction potentials calculated with the Henderson equation are negligible, in the order of few millivolts (Fig. 6a). However, both 
assumptions regarding the activity and the mobility of ions are certainly not valid in highly concentrated solutions. Indeed, theoretical studies recently pointed out that the activity coefficient largely deviates from unity in highly concentrated regimes ${ }^{25}$ while both theoretical and experimental results have shown that diffusion coefficients are greatly dependent on the salt concentration for ions such as $\mathrm{Li}^{+}$for instance. ${ }^{30,31}$
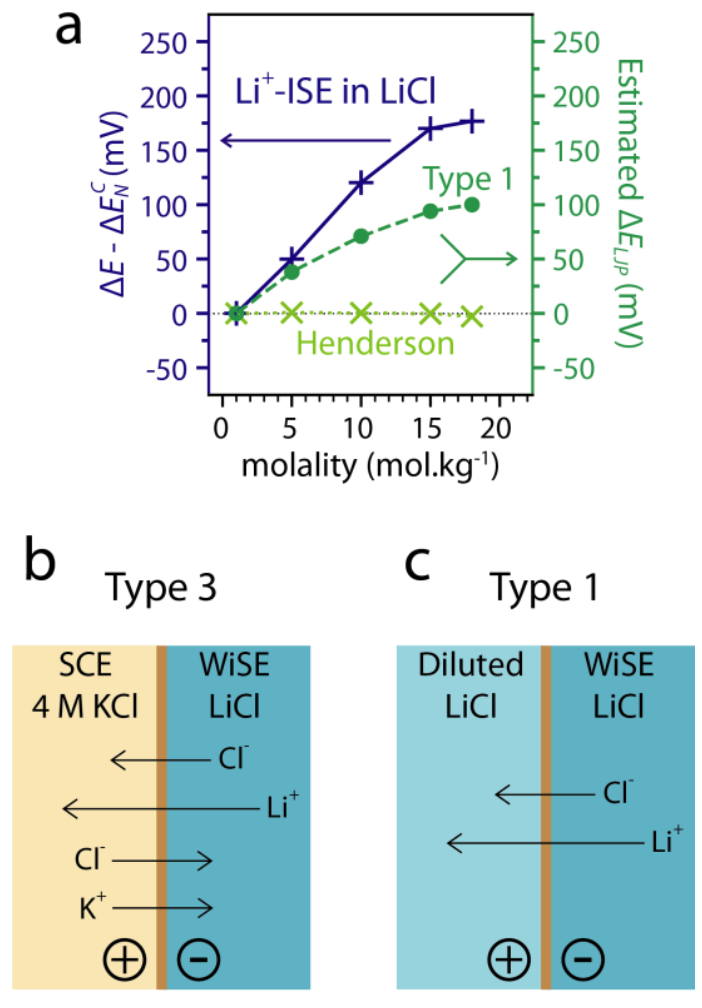

Fig. 6: (a) Comparison of $\left(\Delta E-\Delta E_{N}^{c}\right)$ values measured with a $\mathrm{Li}^{+}$-ISE in LiCl with estimation of the liquid junction potential made using the Henderson equation and Type 1 approximations. (b) Scheme of a Type 3 liquid junction. (c) Scheme of a Type 1 liquid junction.

Evidently, measuring the difference in potentials between the solutions considered in this work and a saturated calomel reference electrode, a Type 3 liquid junction potential is formed for which different types of ions cross the junction in both ways (Fig. 6b) and for which the best approximation is the Henderson equation. ${ }^{27}$ Nevertheless, having established earlier the 
equivalence between our measurements and a concentration cell (Fig. 2), one can tentatively approximate the liquid junction potential to a Type 1 liquid junction potential, i.e. a junction between two solutions of common ions but different concentrations and where ions cross the junction to move to the lower concentration (Fig. 6c) ${ }^{27}$, which is expressed as:

$$
\Delta E_{L J P}=\left(t_{-}-t_{+}\right) \frac{R T}{F} \ln \left(\frac{\gamma_{\text {salt }}(m)}{\gamma_{\text {salt }}\left(m_{\text {Ref }}\right)} \frac{c(m)}{c\left(m_{\text {Ref }}\right)}\right) \#(25)
$$

with $t_{\mathrm{i}}$ the transport number of the ion $i, c(m)$ the concentration of salt at molality $m$ and $\gamma(m)$ the mean activity coefficient of the salt at molality $m \cdot{ }^{27}$ Doing so, two assumptions must once again be made: i) the activity of ions are approximated to be equal to the mean activity of the salt given by the product $c(m) \gamma(m)$ and ii) transport numbers for cations and anions are considered independent of the molality. Considering LiCl solutions with constant transport numbers $\left(t_{+}=0.2 \text { and } t_{-}=0.8\right)^{32}$ and $\gamma(m)$ values previously reported in Ref. 33 and summarized in Table S3, non-negligible values ranging between $40 \mathrm{mV}$ and $100 \mathrm{mV}$ are estimated for the Type 1 junction approximation (Fig. 6a). Observing this, one could conclude that the junction potential accounts for a large part of the shift in potential observed in this work as well as in previous studies switching from diluted to highly concentrated solutions. Nevertheless, the second assumption necessary to apply the Type 1 junction approximation can once again be challenged. Indeed, as previously reported ${ }^{30,32}$ and shown in Fig. S4, the transport numbers for both cations and anions do not remain constant across the concentration range studied in this work. Furthermore, mean activity coefficients are used to estimate the junction potentials for a Type 1 junction, rather than single ions activity coefficients theoretically obtained when using ion selective electrodes. 
Overall, and similarly to the activity of ions, no good approximation currently exist for treating the junction potential in such highly concentrated solutions. Despite such limitations, one can suggest that values close to or greater than $100 \mathrm{mV}$ are found when forming a junction between a 1 mol.kg ${ }^{-1}$ solution and a highly concentrated solutions. Such conclusion is further re-enforced by observing that very similar potential shifts are measured for three very different chemistries - a monovalent alkali-cation $\mathrm{Li}^{+}$, a divalent transition metal $\mathrm{Zn}^{2+}$ and protons - both when the cations studied is diluted in a highly concentrated environment, such as for $\mathrm{Zn}^{2+}$ and protons in LiTFSI, and when the cations of interest are the main cation forming the highly concentrated solutions, as for $\mathrm{Li}^{+}$in LiTFSI solution or $\mathrm{Zn}^{2+}$ in $\mathrm{ZnCl}_{2}$. A common pitfall would thus be to completely neglect the junction potential when studying shift in redox potentials in highly concentrated solutions, or to use a glass electrode $\mathrm{pH}$-meter as previously done to estimate the $\mathrm{pH}$ in LiTFSI solutions as a function of salt molality. ${ }^{27}$ We should rather conclude that, using electrochemical cells in which a liquid junction is formed, the activity coefficients and thus the activity of ions can hardly be extracted in highly concentrated solutions owing to a very large junction potential. This conclusion holds true when using a reference electrode alike the SCE used in this work, as well as when building a concentration cell (Fig. 7a). 
a
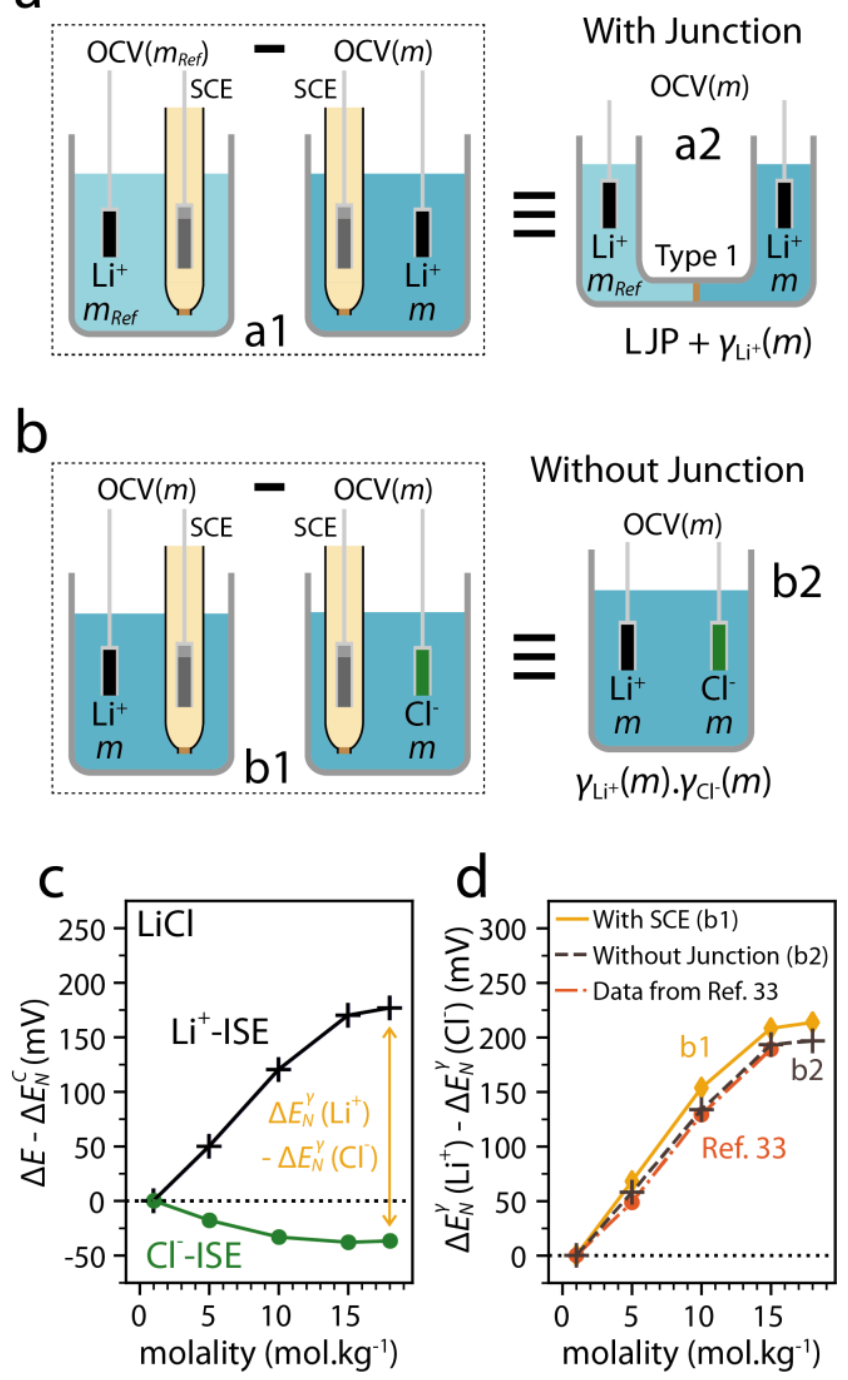

Fig. 7: Schemes representing different cell configurations with or without liquid junction. (a) Concentration cell with a Type 1 liquid junction (a2) and the equivalent configurations using an SCE (a1). (b) Cell without liquid junction using a $\mathrm{Li}^{+}-\mathrm{ISE}$ and $\mathrm{a} \mathrm{Cl}^{-}-\mathrm{ISE}$ (b2) and the equivalent configuration using an SCE (b1). (c) Potential of the $\mathrm{Li}^{+}-\mathrm{ISE}$ and a $\mathrm{Cl}^{-}-\mathrm{ISE}$ in the b1 configuration. (d) Comparison between the calculated shift from Ref 33 with the potential shifts in configurations with SCE (b1) or without SCE (b2).

To be free of any junction potential, potentials can be measured between two ISEs, one being selective to the cation $\left(\mathrm{Li}^{+}\right)$and the other one to the anion $\left(\mathrm{Cl}^{-}\right.$for instance), in the same solution to avoid inducing a junction potential (Fig. 7b):

$$
\mathrm{Li}^{+}-\mathrm{ISE} / \mathrm{LiCl}(m) / \mathrm{Cl}^{-}-\mathrm{ISE}
$$




$$
\mathrm{OCV}(m)=E_{\mathrm{Li}^{+}-\mathrm{ISE}}^{\circ}-E_{\mathrm{Cl}^{-}-\mathrm{ISE}}^{\circ}+\frac{2 R T}{F} \ln (c(m))+\frac{2 R T}{F} \ln \left(\sqrt{\gamma_{\mathrm{Li}^{+}}(m) \gamma_{\mathrm{Cl}^{-}}(m)}\right) \#(26)
$$

While being experimentally convenient, such measurement only gives access to the mean activity coefficients of ions defined as follow:

$$
\gamma_{\mathrm{LiCl}}(m)=\sqrt{\gamma_{\mathrm{Li}^{+}}(m) \gamma_{\mathrm{Cl}^{-}}(m)} \#(27)
$$

and which are commonly obtained by osmotic measurements. ${ }^{33}$ The activity of $\mathrm{Cl}^{-}$was then studied using a $\mathrm{Cl}^{-}$-ISE in LiCl solutions (Fig. S5). In Fig. 7c are reported the $\left(\Delta E-\Delta E_{N}^{c}\right)$ values for the $\mathrm{Cl}^{-}$-ISE and $\mathrm{Li}^{+}$-ISE measured independently against a SCE reference electrode, and their difference (configuration b1 in Fig. 7b) is reported in Fig. 7d along with the data for the equivalent cell (configuration b2 in Fig. 7b) (see details in the SI). Doing so, results overlap with the potential shifts calculated using the average activity coefficients for LiCl solution reported in Ref. 33:

$$
\Delta E_{N}^{\gamma}\left(\mathrm{Li}^{+}\right)-\Delta E_{N}^{\gamma}\left(\mathrm{Cl}^{-}\right)=\frac{2 R T}{F} \ln \left(\frac{\gamma_{\mathrm{LiCl}}(m)}{\gamma_{\mathrm{LiCl}}\left(m_{R e f}\right)}\right) \#(28)
$$

Overall, we demonstrate that electrochemical measurements can reliably provide mean activity coefficients, using two different configurations. Even though mean activity coefficients are useful for certain applications, activity coefficients of single ions are the values of interest to comprehend interfacial redox reactions relevant to electrochemical devices. Unfortunately, they cannot be extrapolated directly from mean activity coefficients. To measure single ion activity coefficient free of any liquid junction potential, quasi-reference electrode such as a Platinum wire calibrated via an internal reference such as the Ferrocenium/Ferrocene couple 
$\left(\mathrm{Fc}^{+} / \mathrm{Fc}\right)$ could be used. ${ }^{27}$ However, doing so the OCV is then expressed as the product of the activities coefficients between the two redox couples:

$$
\begin{gathered}
\mathrm{Li}^{+}-\mathrm{ISE} / \mathrm{LiCl}(m) / \mathrm{Pt} \\
\operatorname{OCV}(m)=E_{\mathrm{Li}^{+}-\mathrm{ISE}}^{\circ}-E_{\mathrm{Fc}^{+} / \mathrm{Fc}}^{\circ}+\frac{R T}{F} \ln \left(c_{\mathrm{Li}^{+}}(m)\right)+\frac{R T}{F} \ln \left(\frac{\gamma_{\mathrm{Li}^{+}}(m) \gamma_{\mathrm{Fc}}(m)}{\gamma_{\mathrm{Fc}^{+}}(m)}\right) \#(29)
\end{gathered}
$$

Hence, such measurement gives access to the product of activity coefficients, alike the combined $\mathrm{Li}^{+}-\mathrm{ISE}$ and $\mathrm{Cl}^{-}$-ISE discussed above (eq. 26). To access single ion activity coefficients for $\mathrm{Li}^{+}\left(\gamma_{\mathrm{Li}^{+}}(m)\right)$ in such configuration, the following must be met: $\gamma_{\mathrm{Fc}}(m)=\gamma_{\mathrm{Fc}^{+}}(m)$, implying that the formal potential of the Ferrocenium/Ferrocene couple is independent on the solution. However, this assumption seems fallacious since the formal potential of Ferrocenium/Ferrocene redox couple is modified by both the nature and the concentration of the salt. ${ }^{34}$ Combined with the low solubility of Ferrocene in aqueous solutions $\left(\approx 10^{-5} \mathrm{~mol}^{-1} \mathrm{~L}^{-1},{ }^{35}\right.$ its use or the use of any other ferrocene derivatives as a proper internal reference should thus be considered with extreme care. Similarly, the use of non-electrochemical means such as molecular probes or $\mathrm{pH}$ paper ${ }^{36}$ does not lead to the formation of a liquid junction. However, this approach only gives access to a product of activity coefficients between the molecular probe and the ion of interest.

\section{Change in proton concentration as a function of salt concentration}

Finally, despite difficulties in extracting the activity for single ions using electrochemical methods, such approach reveals useful to probe changes in concentration of ions in solution. 
Indeed, while $10 \mathrm{mM}$ of $\mathrm{HClO}_{4}$ was added in the previous experiments to fix the concentration of protons, we demonstrate that in the absence of added $\mathrm{HClO}_{4}$, protons concentration is increased from diluted to highly concentrated aqueous solutions. For that, we first compared $\Delta E$ values measured with $1 \mathrm{mM}, 10 \mathrm{mM}$ and $100 \mathrm{mM}$ added protons $\left(\mathrm{HClO}_{4}\right)$ in $\mathrm{LiCl}$ and $1 \mathrm{mM}$ and $10 \mathrm{mM}$ added protons $\left(\mathrm{HClO}_{4}\right)$ in LiTFSI electrolytes using $\mathrm{H}^{+}$-ISE (Fig. 8 and Fig. S6) (due to solubility issues, the measurements with $100 \mathrm{mM}$ of added protons in LiTFSI electrolytes could not be performed across the whole molality range). Aside from the shift of $\approx 150 \mathrm{mV}$ measured from 1 mol. $\mathrm{kg}^{-1}$ to highly concentrated solutions discussed previously, no significant changes are observed between $1 \mathrm{mM}, 10 \mathrm{mM}$ and $100 \mathrm{mM}$ of added protons for $\mathrm{LiCl}$ or between $1 \mathrm{mM}$ and $10 \mathrm{mM}$ of added protons in LiTFSI. One can thus estimate that the proton concentration is fixed by the addition of $\mathrm{HClO}_{4}$. Thus, the $\Delta E_{N}^{c}$ term is null and $\Delta E=\Delta E_{N}^{\gamma}+\Delta E_{L J P}$, i.e. $\Delta E_{N}^{\gamma}+\Delta E_{L J P}$ is independent on the addition of $\mathrm{HClO}_{4}$. This experimental result is rationalized as both the proton activity coefficients and the junction potentials are not expected to drastically change with the addition of small quantities of $\mathrm{HClO}_{4}$ relative to the lithium salt molality. This conclusion is further confirmed by the similar values of $\Delta E-\Delta E_{N}^{c}$ obtained with and without added $\mathrm{HClO}_{4}$ using the Li+ ${ }^{+}$ISE (Fig. S7).

Building upon this result, potentials measured with and without added $\mathrm{HClO}_{4}$ were then compared for LiCl and LiTFSI solutions (Fig. 8a and Fig. 8b, respectively). Doing so, without added protons, an additional shift of $\approx 100 \mathrm{mV}$ is observed compared to the $\Delta E$ values obtained with added protons. It is to be noted that, without the addition of protons and especially at low salt concentration, LiCl and LiTFSI electrolytes are unbuffered media and thus OCV values could vary of a few dozen millivolts rendering any quantitative analysis difficult. However, as 
previously discussed, $\Delta E=\Delta E_{N}^{\gamma}+\Delta E_{L J P}$ with added protons, thus this additional shift originates from a change in the concentration part of the Nernstian potential $\Delta E_{N}^{c}$ as a function of salt concentration when no protons are added. Thus, to account for the additional $\approx 100 \mathrm{mV}$ shift in potential, an increase from one to two orders of magnitude of the proton concentration going from diluted to highly concentrated LiCl and LiTFSI solutions must be invoked.

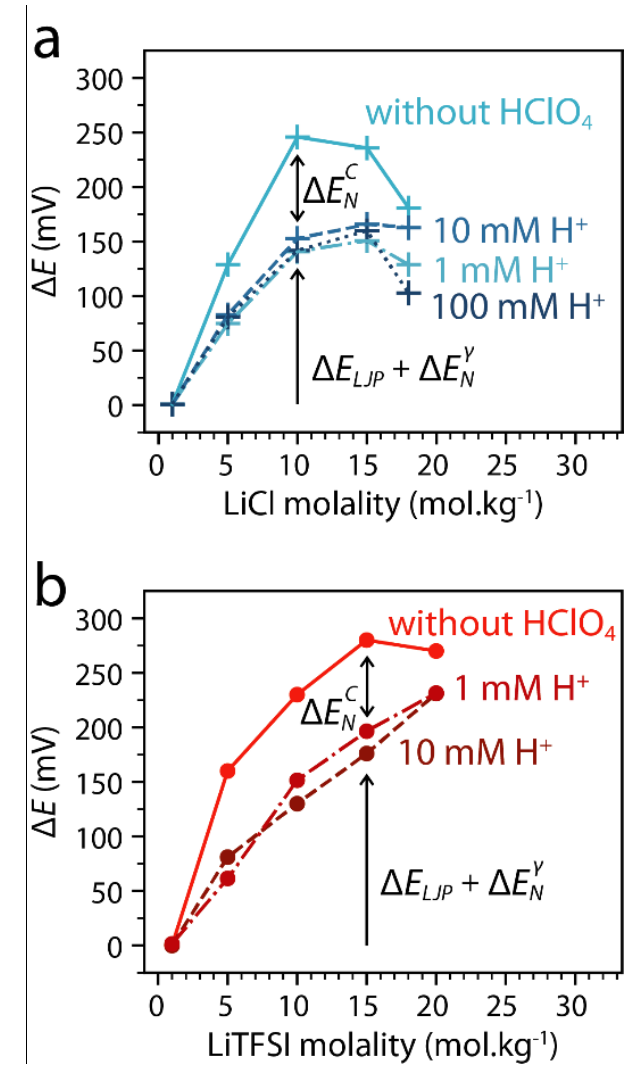

Fig. 8: Evaluation of the proton concentration changes (a) in $\mathrm{LiCl}$ solutions with $1 \mathrm{mM}, 10 \mathrm{mM}, 100 \mathrm{mM}$ or without added $\mathrm{HClO}_{4}$ and (b) in LiTFSI solution with $1 \mathrm{mM}, 10 \mathrm{mM}$ or without added $\mathrm{HClO}_{4}$.

In definitive, we confirm that WiSE are more acidic than classical diluted solutions. Nevertheless, as the addition of $1 \mathrm{mM}$ of $\mathrm{HClO}_{4}$ in WiSEs is sufficient to fix the concentration of protons (i.e. no difference is found between 1, 10 and $100 \mathrm{mM}$ added protons), one can conclude that the concentration of protons in WiSEs is lower than $10^{-3} \mathrm{~mol} . \mathrm{L}^{-1}$. Hence, the shift 
from $\mathrm{pH} 7$ to $\mathrm{pH} 2$ (corresponding to a shift of about $300 \mathrm{mV}$ ) previously reported using a glass $\mathrm{pH}$-meter does not reflect a change in concentration by 5 orders of magnitude of the proton concentration. Moreover, it certainly does not mean that the concentration of protons is equal to $10^{-2} \mathrm{~mol} . \mathrm{L}^{-1}(\mathrm{pH} 2$ in a diluted regime) in highly concentrated aqueous electrolytes. Hence, adopting this electrochemical approach, we highlight that any shift in reversible potential measured with a protons selective electrode in WiSEs should not be discussed with regard to a change of $\mathrm{pH}$, often implicitly understood as a change of proton concentration, but rather be discussed with regards to a change in activity of protons. Furthermore, while we confirm that the activity of protons is increased in WiSEs compared to diluted solutions, this increase originates from both a change in concentration and a change in activity coefficient. Finally, as demonstrated above, an increase of the liquid junction potential contributes to a non-negligible portion of the measured shift in potential and must be considered for any activity measurement in highly concentrated solutions. Unfortunately, this prevents us from gaining quantitative values for activity coefficients in highly concentrated solutions as they are correlated with the junction potential.

\section{Conclusion}

In conclusion, we have established that shift in redox potentials as a function of salt concentration from diluted to highly concentrated regimes measured using ion selective electrodes originates in large from an increased junction potential. This is not to say that the activity coefficients of single ions do not increase as a function of salt concentration, as it 
certainly does, but that such increase cannot be captured by a simple electrochemical method in which a liquid/liquid junction is formed. Such limitation is nested in the dependence of the junction potential on the activity of ions. Furthermore, while electrochemical methods exist to avoid the formation of such junction, they only allow for accessing the mean activity coefficients, alike the ones obtained by osmotic pressure measurements.

While unfortunate for a broad range of fields from bio-electrochemistry to batteries, such conclusion renders futile the search for any electrochemical means to extract activities and/or activity coefficients for individual ions, even though such data is cruelly lacking to validate recent theoretical studies. ${ }^{25}$ Nevertheless, the comparison of potential shifts for a fixed junction potential enable to partially avoid this issue. Doing so, we could demonstrate that protons are indeed created when switching from a diluted to a highly concentrated aqueous electrolytes. Even though quantitative values cannot be estimated, in part owing to the limited stability of these solutions ${ }^{36}$, our results suggest that the proton concentration changes by almost two orders of magnitude from 1 mol. $\mathrm{kg}^{-1}$ to $18 \mathrm{~mol} . \mathrm{kg}^{-1}$ for LiCl or 20 mol. $\mathrm{kg}^{-1}$ for LiTFSI solutions. Finally, this effect will add to the increased activity coefficient for protons and shift the HER towards more positive potentials, counter-balancing the shift towards more positive potentials expected for $\mathrm{Li}^{+}$-based intercalation processes when increasing the Li-salt concentration (Fig. 1b). Thus, for practical applications, the use of highly concentrated Li-based electrolytes does not prevent water reduction, from a thermodynamics point of view, which correlates with previous self-discharge experiments for WiSE batteries. ${ }^{13}$ However, the increased activity coefficients for $\mathrm{Li}^{+}$does displace the solubility equilibrium for solid electrolyte interphase (SEI) inorganic components such as $\mathrm{LiF}^{37}$ and thus slow down interfacial reactivity. Similarly, such 
shift in activity coefficients explain the limited solubility of transition metal halides in superconcentrated electrolytes that we recently uncovered as novel $\mathrm{Li}^{+}$-intercalation compounds. ${ }^{38}$ Overall, such study highlights the difficulties in accurately measuring physical properties of prime importance for assessing the competition existing at the electrode/electrolyte interface between reactions involving ions transfer, as well as for bulkrelated processes involved in electrocatalytic processes such as $\mathrm{CO}_{2}$ reduction. ${ }^{39}$

\section{Experimental section}

\section{Materials \& Methods}

General procedures. The electrolytes were prepared by weighting anhydrous salts (LiCl anhydrous, Alfa Aesar, 99\%; $\mathrm{ZnCl}_{2}$ anhydrous, Alfa Aesar, 98\%; LiTFSI extra dry, Solvionic, 99.9\%) in an Argon filled glovebox (MBraun, $\mathrm{O}_{2}<0.1 \mathrm{ppm}, \mathrm{H}_{2} \mathrm{O}<0.1 \mathrm{ppm}$ ) and by adding the right weight of $\mathrm{HClO}_{4}$ (Sigma-Aldrich, 99.999\%) or $\mathrm{Zn}(\mathrm{TFSI})_{2}$ (anhydrous, Solvionic, 99.5\%) concentrated aqueous solutions and/or Milli-Q water to reach the targeted final composition. Densities were measured using density meter (Anton Paar, DMA 35) in order to convert molalities to concentrations, and vice versa (eq. S21). Densities are reported in SI. All chemicals were used as received without further purification.

Cleaning procedures. All experiments were carried out in electrochemical glass cells at room temperature $\left(\approx 20^{\circ} \mathrm{C}\right)$. Prior to any series of experiments, all glassware was cleaned overnight in 0.5 mol.L ${ }^{-1} \mathrm{H}_{2} \mathrm{SO}_{4}$ (Sigma-Aldrich, 95-98\%) and 1 g.L ${ }^{-1} \mathrm{KMnO}_{4}$ (Alfa Aesar, 98\%), followed by 
rinsing with a dilute $\left(\approx 0.01\right.$ mol. $\left.\mathrm{L}^{-1}\right)$ solution of $\mathrm{H}_{2} \mathrm{SO}_{4}$ (Sigma-Aldrich, 95-98\%) and $\mathrm{H}_{2} \mathrm{O}_{2}$ (SigmaAldricht, $30 \% \mathrm{w} / \mathrm{w}$ ) to remove any traces of $\mathrm{KMnO}_{4}$ and $\mathrm{MnO}_{2}$. Finally, the glassware was rinsed three times and boiled using MilliQ water. The rinsing-boiling procedure was repeated two times.

Electrodes preparation. The $\mathrm{Li}^{+}$-ISE was prepared by pressing on a titanium mesh a mix of carbon coated $\mathrm{LiFePO}_{4}$ (Umicore) and Polytetrafluoroethylene (PTFE, Sigma-Aldricht, 60 wt\% dispersion in water) with a weight ratio of 9:1 which had been dried overnight at $80^{\circ} \mathrm{C}$ under vacuum. The as-prepared electrode was then half charged in a three-electrode cell in a 1 mol.. ${ }^{-1}$ $\mathrm{Li}_{2} \mathrm{SO}_{4}$ aqueous solution in order to reach a stable potential plateau. The $\mathrm{Zn}^{2+}$-ISE consisted of a zinc foil (Alfa Aesar, 99.98\%) polished with three polishing slurries (6 $\mu \mathrm{m}$ diamond on nylon polishing disk, followed by $0.3 \mu \mathrm{m}$ and then $0.04 \mu \mathrm{m}$ aluminium oxide on microcloth polishing disk) using a polishing machine (Presi, Le Cube). The $\mathrm{H}^{+}$-ISE was a polycrystalline platinum disk of $5 \mathrm{~mm}$ diameter at $1600 \mathrm{rpm}$ (Pine Research, $0.196 \mathrm{~cm}^{2}$ geometrical surface area) in solutions continuously bubbled with $\mathrm{H}_{2}$ (Linde, purity 5.5). Prior to any series of measurement, the platinum disk was treated with concentrated nitric acid (VWR, 69\%), then extensively rinsed with Milli-Q water before to be electro-polished in three electrode configuration by scanning between $-0.35 \mathrm{~V}$ vs SCE and $1.45 \mathrm{~V}$ vs SCE at $500 \mathrm{mV} . \mathrm{s}^{-1}$ for 30 scans at $1600 \mathrm{rpm}$ (Pine Research, MSR Rotator) in $0.5 \mathrm{~mol}^{-1} \mathrm{H}_{2} \mathrm{SO}_{4}$ (Sigma-Aldrich, 99.999\%). The $\mathrm{Cl}^{-}-\mathrm{ISE}$ was purchased from Edaq (ET1602 Chloride ions electrode) and used as received.

Data acquisition. Data were acquired on a Biologic VSP potentiostat in solutions with a volume of $10 \mathrm{~mL}$ and de-aerated with $\operatorname{Ar}$ (Linde, purity 5.0) during at least 15 min prior to any measures. The reference electrode was a saturated calomel electrode (OrigaLys, XR110) with a potential 
of $241 \pm 0.5 \mathrm{mV}$ vs RHE (Gaskatel, HydroFlex) in 1 mol. $\mathrm{L}^{-1} \mathrm{H}_{2} \mathrm{SO}_{4}$ (Sigma-Aldricht, 99.999\%). No counter electrode was needed since only OCV were measured. OCV values were determined after waiting up to several hours in order to reach a stable plateau.

\section{Supplementary material}

See the supplementary material for additional data regarding electrolytes and potential shifts.

\section{Acknowledgments}

The authors acknowledge the French National Research Agency for its support through the Labex STORE-EX project (ANR-10LABX-76-01) and through the projects BALWISE (ANR-19-CE050014). N.D. acknowledges the Ecole normale supérieure for his PhD. scholarship.

\section{Data availability}

The data that support the findings of this study are available within the article and its supplementary material. Additional data are available from the corresponding author upon reasonable request.

\section{References}

1. Ellis, R. J. \& Minton, A. P. Join the crowd. Nature 425, 27-28 (2003).

2. Rösgen, J., Pettitt, B. M. \& Bolen, D. W. Protein Folding, Stability, and Solvation Structure in Osmolyte Solutions. Biophys. J. 89, 2988-2997 (2005).

3. Ball, P. Water as an Active Constituent in Cell Biology. Chem. Rev. 108, 74-108 (2008).

4. Karlsson, R. K. B. \& Cornell, A. Selectivity between Oxygen and Chlorine Evolution in the Chlor-Alkali and Chlorate Processes. Chem. Rev. 116, 2982-3028 (2016).

5. Borodin, O., Self, J., Persson, K. A., Wang, C. \& Xu, K. Uncharted Waters: SuperConcentrated Electrolytes. Joule 4, 69-100 (2020). 
6. T. Hong, W. et al. Toward the rational design of non-precious transition metal oxides for oxygen electrocatalysis. Energy Environ. Sci. 8, 1404-1427 (2015).

7. Suo, L. et al. "Water-in-salt" electrolyte enables high-voltage aqueous lithium-ion chemistries. Science 350, 938-943 (2015).

8. Suo, L. et al. Advanced High-Voltage Aqueous Lithium-Ion Battery Enabled by "Water-inBisalt" Electrolyte. Angew. Chem. 128, 7252-7257 (2016).

9. Yamada, Y. et al. Hydrate-melt electrolytes for high-energy-density aqueous batteries. Nat. Energy 1, 1-9 (2016).

10. Ko, S. et al. Lithium-salt monohydrate melt: A stable electrolyte for aqueous lithium-ion batteries. Electrochem. Commun. 104, 106488 (2019).

11. Kühnel, R.-S., Reber, D. \& Battaglia, C. Perspective-Electrochemical Stability of Waterin-Salt Electrolytes. J. Electrochem. Soc. 167, 070544 (2020).

12. Zheng, J. et al. Understanding Thermodynamic and Kinetic Contributions in Expanding the Stability Window of Aqueous Electrolytes. Chem 4, 2872-2882 (2018).

13. Droguet, L., Grimaud, A., Fontaine, O. \& Tarascon, J.-M. Water-in-Salt Electrolyte (WiSE) for Aqueous Batteries: A Long Way to Practicality. Adv. Energy Mater. 10, 2002440 (2020).

14. McEldrew, M., Goodwin, Z. A. H., Kornyshev, A. A. \& Bazant, M. Z. Theory of the Double Layer in Water-in-Salt Electrolytes. J. Phys. Chem. Lett. 9, 5840-5846 (2018).

15. Han, K. S. et al. Origin of Unusual Acidity and Li+ Diffusivity in a Series of Water-in-Salt Electrolytes. J. Phys. Chem. B 124, 5284-5291 (2020).

16. Hubert, H. G. Analytical and Physical Electrochemistry. (2004).

17. Hasted, J. B., Ritson, D. M. \& Collie, C. H. Dielectric Properties of Aqueous Ionic Solutions. Parts I and II. J. Chem. Phys. 16, 1-21 (1948).

18. Levy, A., Bazant, M. \& Kornyshev, A. Ionic activity in concentrated electrolytes: Solvent structure effect revisited. Chem. Phys. Lett. 738, 136915 (2020).

19. Marcus, Y. \& Hefter, G. Ion Pairing. Chem. Rev. 106, 4585-4621 (2006).

20. Borodin, O. et al. Liquid Structure with Nano-Heterogeneity Promotes Cationic Transport in Concentrated Electrolytes. ACS Nano 11, 10462-10471 (2017).

21. Dubouis, N. et al. Chasing Aqueous Biphasic Systems from Simple Salts by Exploring the LiTFSI/LiCl/H2O Phase Diagram. ACS Cent. Sci. 5, 640-643 (2019).

22. Pitzer, K. S. Thermodynamics of electrolytes. I. Theoretical basis and general equations. $J$. Phys. Chem. 77, 268-277 (1973).

23. Pitzer, K. S. \& Mayorga, G. Thermodynamics of electrolytes. II. Activity and osmotic coefficients for strong electrolytes with one or both ions univalent. J. Phys. Chem. 77, 2300-2308 (1973).

24. Pitzer, K. S. \& Mayorga, G. Thermodynamics of electrolytes. III. Activity and osmotic coefficients for 2-2 electrolytes. J. Solut. Chem. 3, 539-546 (1974).

25. McEldrew, M., Goodwin, Z. A. H., Bi, S., Bazant, M. Z. \& Kornyshev, A. A. Theory of ion aggregation and gelation in super-concentrated electrolytes. J. Chem. Phys. 152, 234506 (2020).

26. Hamer, W. J. \& Wu, Y. Osmotic Coefficients and Mean Activity Coefficients of Uni- univalent Electrolytes in Water at $25^{\circ}$ C. J. Phys. Chem. Ref. Data 1, 1047-1100 (1972).

27. Bard, A. J. \& Faulkner, L. R. Electrochemical Methods: Fundamentals and Applications, 2nd Edition. (2000). 
28. Wandt, J., Lee, J., Arrigan, D. W. M. \& Silvester, D. S. A lithium iron phosphate reference electrode for ionic liquid electrolytes. Electrochem. Commun. 93, 148-151 (2018).

29. Wang, F. et al. Highly reversible zinc metal anode for aqueous batteries. Nat. Mater. 17, 543-549 (2018).

30. Li, Z. et al. Transport Properties of Li-TFSI Water-in-Salt Electrolytes. J. Phys. Chem. B 123, 10514-10521 (2019).

31. Tanaka, K. \& Nomura, M. Measurements of tracer diffusion coefficients of lithium ions, chloride ions and water in aqueous lithium chloride solutions. J. Chem. Soc. Faraday Trans. 1 Phys. Chem. Condens. Phases 83, 1779-1782 (1987).

32. Chapman, T. W. \& Newman, J. A Compilation of Selected Thermodynamic and Transport Properties of Binary Electrolytes in Aqueous Solution. (1968).

33. Lide, D. R. et al. CRC Handbook of Chemistry and Physics. 2661.

34. Torriero, A. A. J. \& Howlett, P. C. Ionic liquid effects on the redox potential of ferrocene. Electrochem. Commun. 16, 84-87 (2012).

35. Wu, J.-S., Toda, K., Tanaka, A. \& Sanemasa, I. Association Constants of Ferrocene with Cyclodextrins in Aqueous Medium Determined by Solubility Measurements of Ferrocene. Bull. Chem. Soc. Jpn. 71, 1615-1618 (1998).

36. Reber, D., Figi, R., Kühnel, R.-S. \& Battaglia, C. Stability of aqueous electrolytes based on LiFSI and NaFSI. Electrochimica Acta 321, 134644 (2019).

37. Dubouis, N. et al. The role of the hydrogen evolution reaction in the solid-electrolyte interphase formation mechanism for "Water-in-Salt" electrolytes. Energy Environ. Sci. 11, 3491-3499 (2018).

38. Dubouis, N. et al. Superconcentrated Electrolytes Widens Insertion Electrochemistry to Soluble Layered Halides. Nat. Mater. (2021) doi:10.1038/s41563-021-01060-w NM21030925.

39. Nesbitt, N. \& Smith, W. Water Activity Regulates CO2 Reduction in Gas-Diffusion Electrodes. (2021) doi:10.26434/chemrxiv.13571141.v1. 